\title{
Pengembangan program psikoedukasi untuk mengelola stres, cemas, dan depresi pada mahasiswa yang sedang menempuh skripsi
}

-ISSN 2746-8976; e-ISSN 2685-8428 ejournal.umm.ac.id/index.php/cognicia 2021, Vol 9(1):1-5

DOI:10.22219/cognicia.v9i1.15130

(C)The Author(s) 2021

(c)(1) 4.0 International license

\section{Zainul Anwar ${ }^{1}$ dan Djudiyah ${ }^{1}$}

\begin{abstract}
Some students, working on a thesis is a "scourge" because they have to do it themselves and interact personally with other people. This is where students sometimes feel depressed, anxious, and depressed because of the various problems they face. One of the strategies used is to provide psychoeducation programs that are relevant to the problem. The research objective is to find a problem and a psychoeducation model for that problem. The research method used is descriptive quantitative, the subject was taken purposively as many as 63 respondents and descriptive analysis. The results found includes: (a) The main problems are communication with supervisors, self-management and time, looking for references, low motivation, writing a thesis according to APA Style, and economic and family issues, and (b) Psychoeducation program model with achievement motivation training material, persuasive communication training, training program applications quotes, and especially for those who need special treatment, the counseling or psychotherapy process is carried out individually.
\end{abstract}

\section{Keywords}

Psychoeducation program, stress, anxiety, depression, college students

\section{Pendahuluan}

Proses pembelajaran di perguruan tinggi memiliki persyaratan khusus agar mahasiswa dapat menyelesaikan studinya, salah satu proses yang harus ditempuh, yaitu menyelesaikan tugas akhir atau skripsi sebagai proses salah satu evaluasi studi yang telah diamanatkan dalam peraturan pemerintah. Sebagaimana ditetapkan dan diatur dalam Peraturan Pemerintah Republik Indonesia (1999) Bab 5 tentang penilaian hasil belajar pasal 15 dan pasal 16 yaitu "Ujian dapat diselenggarakan melalui ujian semester, ujian akhir program studi, ujian skripsi, ujian tesis, dan ujian disertasi" dan "Ujian akhir program studi suatu program sarjana dapat terdiri atas ujian komprehensif atau ujian karya tulis, atau ujian skripsi”.

Dengan adanya peraturan tersebut, tentu mahasiswa wajib mengerjakan skripsi, bagi sebagian mahasiswa hal itu terlihat biasa-biasa saja dan menjadi tantangan tersendiri, namun bagi sebagian mahasiswa yang lain juga menjadi "momok" karena harus mengerjakan sendiri dan berinteraksi secara pribadi dengan orang lain atau pembimbing. Disinilah mahasiswa dituntut untuk mandiri, berinisiatif, bertanggung jawab dan bekerja keras untuk menyelesaikan tugas akhirnya.

Mahasiswa merupakan salah satu unsur penting dari civitas akademika selama menempuh pembelajaran di Perguruan Tinggi. Mahasiswa juga merupakan calon pemimpin dimasa yang akan datang sehingga menjadi salah satu unsur penting untuk kemajuan bangsa dan Negara, oleh sebab itu diharapkan mahasiswa memiliki pola pikir yang positif, mental yang kuat, personality tangguh serta jiwa yang bersih sehingga tidak mudah stress, namun tetap tenang dan semangat dalam menjalankan tugas-tugasnya.
Sebagai insan akademisi diharapkan mampu mengelola problem yang dihadapinya, tentunya mahasiswa selama belajar di perguruan tinggi banyak problem yang harus dihadapi, karena berbagai tuntutan yang harus diselesaikan, mulai dari tuntutan penyesuaian diri dengan lingkungan sampai pada tuntutan tugas-tugas akademik yang harus ia selesaikan. Semua problem yang dihadapi mahasiswa pada hakikatnya adalah sebagai proses belajar agar dirinya lebih kuat dalam menghadapi kenyataan hidup ketika ia lulus.

Beberapa hasil penelitian menunjukkan bahwa kejadian mahasiswa bunuh diri atau mencoba untuk mengakhiri hidup karena banyaknya masalah yang dihadapi dan tidak kuat untuk mengelola masalahnya yang membuat mahasiswa menjadi tertekan, mengalami kecemasan, bahkan sampai mengalami depresi, hal tersebut membuat sangat penting untuk menjadi perhatian (Kholidah \& Alsa, 2012). Selain itu, mahasiswa yang sedang mengerjakan tugas akhir juga banyak yang mengalami prokrastinasi karena banyaknya dan kuatnya tekanan yang dialaminya (Gunawati et al., 2010). Hasil riset Joseph (2009) menemukan beberapa hal yang membuat mahasiswa menjadi tertekan, antara lain karena adanya time management yang kurang baik, banyaknya tekanan berupa tugas-tugas akademik yang tidak sedikit, lingkungan belajar yang kurang kondusif. Kemudian juga ditemukan mahasiswa yang mengalami tekanan kuat lebih banyak dialami mahasiswi dibanding dengan mahasiswa.

\footnotetext{
${ }^{1}$ Universitas Muhammadiyah Malang

Korespondensi:

Zainul Anwar, Fakultas Psikologi Universitas Muhammadiyah Malang

Email: zainulanwar@umm.ac.id
} 
Stres adalah bentuk respon psikologis yang umum terjadi ketika seseorang mengalami atau merespon stimulus dan itu normal terjadi pada setiap orang, namun ketika stres-nya tidak mampu ia kelola akan membuat hidupnya bermasalah. Setiap manusia akan selalu berusaha secara maksimal dalam mnegelola stresnya karena itu sudah menjadi fitrah manusia untuk selalu berusaha melakukan penyesuaian diri agar tetap mampu untuk bertahan hidup (Potter \& Perry, 2005).

Mahasiswa sebagai insan akademis tentunya harus bertanggung jawab dalam menjalankan tugas-tugasnya, tentunya berbagai tekanan akademik dan non akademik akan menjadi bagian selama proses belajar di Perguruan Tinggi sehingga hal tersebut menjadi stressor tersendiri bagi mahasiswa (Potter \& Perry (2005); Smeltzer et al. (2008)). Kajian pustaka pada mahasiswa yang sedang menempuh studi di Perguruan Tinggi ditemukan banyak yang mengalami stress dengan kategori tinggi, bahkan secara kuantitatif cenderung mengalami peningkatan tiap semesternya yang lebih banyak karena adanya academic stress. Hal ini karena adanya keadaan tertekan yang dialam oleh mahasiswa dan berhubungan dengan ilmu yang sedang dipelajarinya di Perguruan Tinggi tersebut (Govaerts \& Grégoire, 2004).

Kajian riset mengenai stressor pada insan akademisi yang sedang menuntut ilmu di Perguruan Tinggi banyak terjadi karena adanya mahasiswa yang kurang mampu dalam mengelola tugas-tugas akademiknya sehingga membuat prestasinya menurun disebabkan seringnya menunda-nunda penyelesaian berbagai tugas-tugas akademiknya (Purwati, 2012). Selain adanya dampak negatif tersebut, sebenarnya stress juga memiliki dampak positif jika mampu mengelola stresnya dengan baik, seperti akan termotivasi atau terpacu untuk segera menyelesaikan tugas-tugas akademiknya, oleh karena itu pada dasarnya stress tetap dibutuhkan oleh mahasiswa dengan tetap berusaha untuk mengelolanya. Respon stres tiap mahasiswa tentunya berbeda-beda. Respon tersebut sangat tergantung dengan kemampuan mental masing-masing mahasiswa dan juga adanya peristiwa terdahulu yang mempengaruhinya terhadap stress, coping mechanism, gender, umur, besar kecilnya tekanan, dan kemampuan mengelola emosi tiap-tiap mahasiswa (Potter \& Perry (2005); Smeltzer et al. (2008)).

Untuk mengatasi masalah tersebut dibutuhkan strategi pengelolaan diri agar mahasiswa tetap mampu mengelola stresnya. Salah satu strategi yang digunakan yaitu dengan pemberian psikoedukasi tentang manajemen diri, agar mahasiswa mampu memahami dan melakukan apa yang harus dilakukan dalam menyelesaikan studinya. Salah satunya berupa program psikoedukasi, yaitu aktivitas positif yang disampaikan oleh tenaga ahli dalam menyatukan dan mengelola dengan baik dalam memberikan penanganan (Cartwright, 2007)

Temuan Suryani et al. (2016) psikoedukasi ditemukan efektif untuk menurunkan tingkat stress, anxiety, dan depressive khusus pada pasien tuberculosis. Selain itu, penelitian yang dilakukan oleh Asra (2013) menjelaskan bahwa temuannya juga efektif menggunakan program psikoedukasi pada remaja yang mengalami mental retardation ringan dalam rangka untuk meningkatkan wawasan dan pemahaman tentang seksual. Adapun tujuan penelitian ini, yaitu untuk menemukan program psikoedukasi yang tepat dalam mengelola tingkat stres, cemas, dan depresi pada mahasiswa yang sedang menempuh skripsi. Manfaatnya mahasiswa dapat mengelola dirinya dengan tetap semangat mengerjakan tugas akademik berupa penyelesaian tugas akhir atau skripsi.

\section{Stres, Cemas, dan Depresi}

Stres merupakan keadaan stres fisik dan psikologis karena adanya berbagai tekanan baik dari internal sendiri dan eksternalnya. Seseorang dapat dikatakan mengalami stres, ketika seseorang mengalami keadaan tekanan batin akibat tuntutan yang datang dari dalam dirinya dan lingkungan. Selain memiliki efek negatif dan stres juga memiliki efek positif. Stres yang memiliki efek buruk biasa dikatakan dengan istilah distress dan stres yang memiliki efek baik biasa dikatakan dengan istilah eustress. Perbedaan efek stres lebih dipengaruhi karena adanya keunikan tiap-tiap orang, sehingga respon masing-masing orang tidak sama antara orang satu dengan lainnya meskipun stimulusnya sama atau stresornya sama (Rathus \& Nevid, 2002).

Tiap-tiap orang memiliki pemikiran dan respon yang berbeda dalam mengelola stres. Pemikiran individu seringkali dilandaskan pada keyakinan-keyakinan dan normanorma yang ada, peristiwa masa lalu dan gaya hidup, faktorfaktor lingkungannya, struktur dan fungsi-fungsi keluarga, tahapan-tahapan perkembangan dalam keluarga, peristiwa terdahulu dengan stres dan coping mechanism. Level stres terbagi menjadi lima tingkatan menurut Crawford \& Henry (2003) dan Psychology Foundation of Australia (2014), yaitu; normal stress, light stress, moderate stress, severe stress, dan very heavy stress.

Cemas adalah kondisi emosi yang ditandai dengan gairah physiological, ketegangan emosi yang tidak mengenakkan, dan perasaan umum bahwa sesuatu yang tidak diharapkan akan muncul (Rathus \& Nevid, 2002). Arnold \& Nieswiadomy (2005) dalam teori Peplau mengidentifikasi empat level cemas, yaitu; mild anxiety, moderate anxiety, severe anxiety, dan panic.

Depresi merupakan abnormalitas dengan adanya kriteria atau karakteristik mood menurun, pesimisme, hilangnya spontanitas dan gejala-gejala faal lainnya (Kring, Johnson, \& Davison, 2012). Menurut Rathus \& Nevid (2002), karakteristik secara umum dari depresi antara lain: (a) perubahan keadaan emosi, (b) perubahan motivasi, (c) perubahan fungsi dan perilaku motorik, dan (d) perubahan kognitif.

\section{Psikoedukasi}

Psikoedukasi merupakan salah satu strategi penanganan yang dapat diterapkan pada setting individual, family, dan group yang fokus pada edukasi psikologis partisipan tentang berbagai problem yang dihadapi dalam hidup, menolong orang lain agar lebih mampu mengembangkan berbagai sumber dukungan-dukungan dari lingkungannya, serta mengembangkan coping skill untuk mengelola berbagai masalah (Walsh, 2010).

Sedangkan Nelson-Jones menguraikan psikoedukasi memiliki enam makna, antara lain: (1) melatihkan berbagai keterampilan hidup, (2) academic approach atau pengalaman untuk mengajarkan ilmu-psikologi, (3) humanistic education, (4) melatihkan para profesional di 
bidang counseling skill, (5) serangkaian aktivitas layanan pada masyarakat, (6) melakukan edukasi mengenai ilmupsikologi pada publik (Supratiknya, 2011).

Adapun psikoedukasi dalam penelitian ini yaitu psikoedukasi manajemen diri berupa suatu intervensi yang diberikan kepada mahasiswa yang sedang menempuh skripsi dengan beberapa program pelatihan seperti pelatihan relaksasi, manajemen diri, strategi bimbingan skripsi (mengenal dan memahami dosen pembimbing) dan strategi penulisan skripsi (menemukan ide penelitian, internet sebagai sumber belajar, searching journal untuk dijadikan referensi, serta memanfaatkan aplikasi sitasi dalam penulisan skripsi).

\section{Metode}

\section{Subjek Penelitian}

Metode penelitian yang digunakan berupa penelitian deskriptif kuantitatif dengan subjek penelitian sebanyak 63 responden. Subjek diambil secara purposive dengan ketentuan mahasiswa yang telah menyelesaikan skripsi (maksimal satu bulan setelah ujian skripsi) agar masih dapat mengingat pengalaman selama proses mengerjakan skripsi. Pengambilan data menggunakan metode yang saling melengkapi, meliputi kuesioner, interview, dan Focus Group Discussion.

\section{Variabel dan Instrumen Penelitian}

Instrumen psikologi digunakan untuk menskrining problem mahasiswa. Wawancara dan FGD digunakan untuk mengetahui problem yang dialami secara mendalam. Data yang digunakan dalam penelitian ini adalah data primer dan sekunder. Data primer mencakup data hasil kuesioner, FGD, dan wawancara. Sedangkan data sekunder adalah datadata dari dokumen yang dimiliki subjek penelitian, seperti kemampuan kognitif berupa data laporan prestasi akademik.

\section{Analisis Data}

Analisis data dilakukan secara sistematis dengan pemilahan data mentah berdasarkan timing pengambilan data dan cara pengambilan data. Selanjutnya data diberi kode berdasarkan kebutuhan analisis. Selanjutnya melakukan analisis tematik dan dilanjutkan perbandingan dengan tinjauan pustaka dan digunakan sebagai dasar untuk menyusun model dengan menggabungkan antara teori dan data yang dihasilkan.

\section{Hasil}

Berdasarkan hasil penelitian didapatkan subjek yang bersedia menjadi responden sebanyak 63 responden. Adapun prosentasi lama waktu dalam pengerjaan skripsi, yaitu sebanyak 39,7\% ( $1-6$ bulan), 38,1\% ( $1-12$ bulan), 7,9\% (1 -24 bulan), 6,3\% ( $1-18$ bulan), 6,3\% ( $>3$ tahun), 1,6\% (1 - 36 bulan), dan 0,1 ( 1 - 30 bulan). Kemudian untuk tingkat stres selama mengerjakan skripsi, yaitu tingkat stress sangat tinggi sebanyak $17,5 \%$, tingkat stres tinggi sebanyak 52\%, , tingkat stress sedang 15,9\%, tingkat stress rendah $12,7 \%$, dan tingkat stress sangat rendah sebanyak 1,6\%. Faktor utama yang menyebabkan stress antara lain manajemen dan motivasi diri sebanyak $35 \%$, dosen pembimbing $25 \%$, kesulitan mencari referensi $21 \%$, kesulitan membagi waktu
$8 \%$, masalah keluarga $6 \%$, dan mencari judul $5 \%$. Tingkat cemas selama mengerjakan skripsi yaitu sebanyak $52,4 \%$ tergolong tingkat cemas yang tinggi, 22,2\% tingkat cemas sedang, $15,9 \%$ tingkat cemas sangat tinggi, $7,9 \%$ tingkat cemas rendah, dan 1,6\% tingkat cemas sangat rendah. Faktor utama yang menyebabkan cemas yaitu khawatir tidak sesuai target sebanyak 43\%, khawatir ketika bimbingan dimarahi dosen sebanyak 19\%, khawatir kesulitan mencari literatur sebanyak $16 \%$, tidak ada yang perlu dikhawatirkan $11 \%$, dan khawatir salah dalam mengerjakan skripsi sebanyak $9 \%$.

Tingkat depresi selama mengerjakan skripsi antara lain sebanyak 23,8\% tingkat depresi sangat rendah, 19\% tingkat depresi rendah, $19 \%$ tingkat depresi sedang, 23,8\% tingkat depresi tinggi, dan sebanyak 14,3\% tingkat depresi sangat tinggi. Faktor utama yang menyebabkan depresi yaitu sebanyak $30 \%$ tidak ada yang membuat depresi, $22 \%$ takut salah dan dimarahi oleh dosen pembimbing, $21 \%$ kesulitan menghilangkan malas, $16 \%$ skripsi tidak mendapat acc dosen pembimbing, 9\% tidak sesuai dengan target dan dimarahi keluarga, dan $1 \%$ takut dengan masa depan yang tidak jelas.

Adapun problem utama selama mengerjakan skripsi yaitu komunikasi dengan dosen pembimbing, manajemen diri dan waktu, mencari referensi, motivasi rendah, dan menulis skripsi sesuai APA style. Berdasarkan hasil identifikasi dan analisis problem dapat disusun model pengembangan program psikoedukasi sebagaimana Gambar 1

\section{Diskusi}

Hasil identifikasi problem utama bagi mahasiswa yang sedang menyelesaikan skripsi meliputi; komunikasi dengan dosen pembimbing, manajemen diri dan waktu, mencari referensi, motivasi rendah, menulis skripsi sesuai APA style, masalah ekonomi dan keluarga. Sedangkan tingkat stres dan cemas rata-rata berada pada kategori tinggi, serta kategori sedang untuk tingkat depresi.

Salah satu strategi dalam mengatasi problem tersebut adalah dengan melakukan psikoedukasi agar problem dapat tertangani. Beberapa penelitian tentang psikoedukasi telah banyak dilakukan dengan berbagai variasinya dan menunjukkan hasil yang memuaskan sehingga perlu juga dikembangkan sebuah model psikoedukasi yang juga dapat

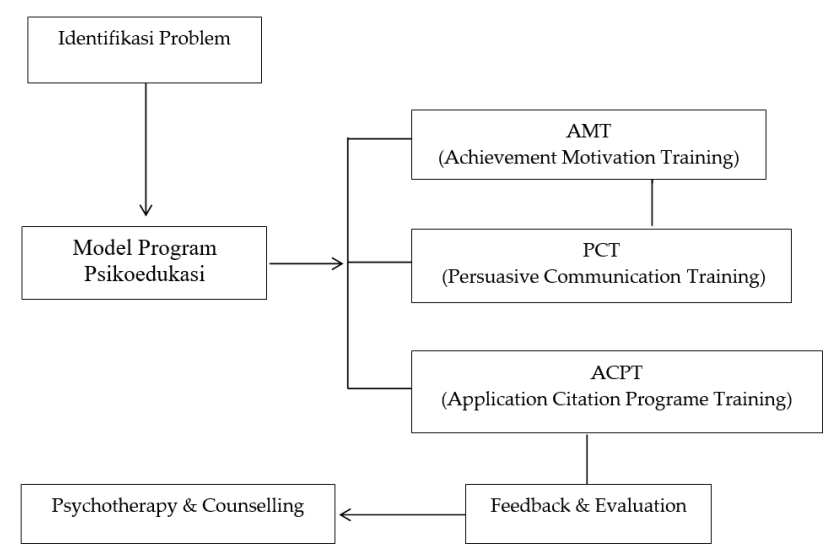

Gambar 1. Tahapan - tahapan program psikoedukasi pada mahasiswa yang sedang menempuh skripsi 
membantu mahasiswa dalam menangani berbagai problem yang sedang dihadapinya selama mengerjakan skripsi.

Hasil penelitian juga relevan dengan hasil penelitian Suryani et al. (2016) bahwa program psikoedukasi yang diterapkan pada pasien tuberculosis juga efektif untuk mengurangi tingkat stress, anxiety, dan depressive. Program psikoedukasi yang dilaksanakan berupa program psikoedukasi aktif dan pasif. Program psikoedukasi aktif dalam bentuk konseling, sedangkan psikoedukasi pasif berupa diberikan buku saku pada partisipan. Pada penelitian ini juga disusun program-program berupa pertemuan langsung baik berupa pelatihan ataupun konseling, serta buku saku bagi partisipan.

Penelitian tentang pemberian program psikoedukasi juga dilakukan Arnold \& Nieswiadomy (2005), yaitu psikoedukasi yang dilakukan terhadap orang tua berupa training dan diberikannya panduan untuk meningkatkan pemahaman tentang perilaku seksual bagi remaja yang mengalami mental retardation moderate, hasilnya juga memberikan dampak positif atau efektif dengan diberikannya program psikoedukasi.

Program psikoedukasi yang dilakukan pada guru juga efektif untuk meningkatkan pengetahuan dan keterampilan guru dalam menangani bullying, meningkatkan self-efficacy, dan manajemen kelas untuk mengurangi bullying. Materi psikoedukasi ini meliputi pengetahuan secara umum tentang bullying (bentuk perilaku, pelaku, korban, dan penonton), cara pendampingan (korban dan penonton), cara mengintervensi pelaku, manajemen kelas dan keterampilan untuk melakukan relaksasi (Newman et al., 2004); (Nugroho \& Adiyanti, 2011).

Penelitian Anwar \& Rahmah (2017) bahwa psikoedukasi yang diberikan kepada remaja mampu menurunkan intensi untuk menikah dini. Hal ini menguatkan kebermanfaatan psikoedukasi untuk berbagai persoalan. Teori-teori yang digunakan dalam psikoedukasi antara lain adalah teori sistem ekologi, teori kognitif-perilaku, teori belajar, group practice models, stress and coping models, model dukungan sosial, serta pendekatan naratif (Lukens \& McFarlane (2004); Anwar \& Rahmah (2017).

Model psikoedukasi pada penelitian ini berfokus pada sisi positif responden yang berorientasi pada masa sekarang dan masa yang akan datang serta menjadikan masa lalu sebagai pelajaran. Program psikoedukasi dapat juga diberikan secara pribadi ataupun group pada berbagai tingkat usia maupun pendidikan, isi materi yang diberikan tidak hanya bersifat penyampaian pengetahuan terkait problem tapi lebih dari itu, juga dapat diberikan pelatihan-pelatihan yang dibutuhkan oleh partisipan agar dirinya dapat lebih berkembang secara optimal.

Brown (2018) menguraikan psikoedukasi kelompok lebih menekankan pada proses belajar dan pendidikan dari pada self-awareness dan self-understanding dimana komponen kognitif memiliki proporsi yang lebih besar dari pada komponen afektif. Berdasarkan kajian tersebut, model psikoedukasi yang dikembangkan meliputi a) identifikasi problem dan b) model program psikoedukasi achievement motivation training, persuasive communication training, application citation program training, psychotherapy dan counseling.

\section{Kesimpulan}

Kesimpulan yang dapat diambil dari penelitian yaitu berupa problem utama mahasiswa dalam penyelesaian skripsi, antara lain komunikasi dengan dosen pembimbing, manajemen diri dan waktu, mencari referensi, motivasi rendah, menulis skripsi sesuai APA Style, dan masalah ekonomi dan keluarga. Selain itu, sebagai bentuk penanganan atas masalah tersebut perlu adanya program psikoedukasi dengan materi tentang achievement motivation training, persuasive communication training, application citation program training, dan khusus bagi yang membutuhkan penanganan khusus dilakukan proses konseling atau psikoterapi secara individual.

\section{Referensi}

Antony, M. M., Bieling, P. J., Cox, B. J., Enns, M. W., \& Swinson, R. P. (1998). Psychometric properties of the 42-item and 21-item versions of the Depression Anxiety Stress Scales in clinical groups and a community sample. Psychological Assessment, 10(2), 176-177.

Anwar, Z., \& Rahmah, M. (2017). Psikoedukasi tentang resiko perkawinan usia muda untuk menurunkan intensi pernikahan dini pada remaja. Psikologia: Jurnal Psikologi, 1(1), 1-14. https://doi.org/10.21070/psikologia.v1i1.749

Arnold, W. K., \& Nieswiadomy, R. (2005). Peplau's theory with an emphasis on anxiety. Theory-Directed Nursing Practice, 171-199.

Asra, Y. K. (2013). Efektivitas psikoedukasi pada orangtua dalam meningkatan pengetahuan seksualitas remaja retardasi mental ringan. Jurnal Psikologi, 9(1), 64-72. http://dx.doi.org/10.24014/jp.v9i1.149

Beck, A. T., Steer, R. A., \& Brown, G. K. (1996). Beck depression inventory-II. San Antonio, 78(2), 490-498.

Buunk B., \& Vugt, M. V. (2008). Applying social psychology: From problems to solutions. Singapore: Sage Publication.

Brown, N. W. (2018). Psychoeducational groups: Process and practice. Routledge. Taylor \& Francis Group.

Cartwright, M. (2007). Psychoeducation among caregivers of children receiving mental health services. The Ohio State University.

Crawford, J. R., \& Henry, J. D. (2003). The Depression Anxiety Stress Scales (DASS): Normative data and latent structure in a large non-clinical sample. British Journal of Clinical Psychology, 42(2), 111-131.

Govaerts, S., \& Grégoire, J. (2004). Stressful academic situations: Study on appraisal variables in adolescence. Revue Européenne de Psychologie Appliquee, 54(4), 261-271. https://doi.org/10.1016/j.erap.2004.05.001

Gunawati, R., Hartati, S., \& Listiara, A. (2010). Hubungan antara efektivitas komunikasi mahasiswa-dosen pembimbing utama skripsi dengan stres dalam menyusun skripsi pada mahasiswa program studi psikologi fakultas kedokteran universitas diponegoro. Jurnal Psikologi, 3(2), 93-115.

Joseph, E. (2009). An assessment of academic stress among undergraduate students: The case of University of Botswana. Educational Research and Reviews, 4(2), 63-70.

Kholidah, E., \& Alsa, A. (2012). Berpikir positif untuk menurunkan stres psikologis. Jurnal Psikologi, 39(1), 67-75. https://doi.org/10.22146/JPSI.6967 
Kring, A., Johnson, S., \& Davison, G. C. (2012). Abnormal psychology. Wiley Global Education.

Lukens, E. P., \& McFarlane, W. R. (2004). Psychoeducation as evidence-based practice: considerations for practice, research, and policy. Brief Treatment \& Crisis Intervention, 4(3), 205-225. https://doi.org/10.1093/brief-treatment/mhh019

Newman, D., Carlson, D., \& Horne, M. A (2004). Bully busters: A psychoeducational intervention for reducing bullying behavior in middle school students. Journal of Counseling And Development, 83, 259-265.

Nugroho, S., \& Adiyanti, M. G. (2011). Program psikoedukasi untuk meningkatkan pengetahuan dan keterampilan guru dalam menangani bullying. JIP (Jurnal Intervensi Psikologi), 3(1), 25-48. https://doi.org/10.20885/intervensipsikologi.vol3.iss1.art2

Pemerintah Republik Indonesia (1999). Peraturan pemerintah republik indonesia nomor 60 tahun 1999 tentang pendidikan tinggi. Jakarta.

Potter, P. A., \& Perry, A. G. (2005). Buku ajar fundamental keperawatan: Konsep, proses, dan praktik. Jakarta: EGC.
Psychology Foundation of Australia. (2014). Depression anxiety stress scale.42-43.

Purwati, S. (2012). Tingkat stres akademik pada mahasiswa reguler angkatan 2010 Fakultas Ilmu Keperawatan Universitas Indonesia. 21-22.

Rathus, S. A., \& Nevid, J. S. (2002). Psychology and the challenges of life: adjustment in the new millennium. John Wiley.

Smeltzer, S. C., Bare, B. G., Hinkle, J. L., Cheever, K. H., Townsend, M. C., \& Gould, B. (2008). Brunner and suddarth's textbook of medical surgical nursing 10th edition. Philadelphia: Lipincott Williams \& Wilkins.

Supratiknya, A. (2011). Merancang program dan modul psikoedukasi. Yogyakarta: Penerbit Universitas Sanata Dharma.

Suryani, E. W., Hernawati, T., \& Sriati, A. (2016). Psikoedukasi menurunkan tingkat depresi, stres dan kecemasan pada pasien tuberkulosis paru. Jurnal Ners, 11(1), 128-133.

Walsh, J. F. (2010). Psychoeducation in mental health. Lyceum Books. 